\title{
Adolescência através dos Séculos
}

\author{
Teresa Helena Schoen-Ferreira ${ }^{1}$ \\ Maria Aznar-Farias \\ Universidade Federal de São Paulo \\ Edwiges Ferreira de Mattos Silvares \\ Universidade de São Paulo
}

\begin{abstract}
RESUMO - A sociedade contemporânea ocidental estendeu o período da adolescência, que não é mais encarada apenas como uma preparação para a vida adulta, mas passou a adquirir sentido em si mesma, como um estágio do ciclo vital. O presente artigo procura descrever como os adolescentes eram vistos e tratados, desde a antiguidade até os dias de hoje, a partir de textos literários ou filosóficos e estudos científicos. O material bibliográfico a respeito da adolescência caracteriza-se por três etapas distintas: a descrição dos padrões de comportamento, ajustamento pessoal e relacionamento; a resolução de problemas reais por meio do conhecimento científico; e o desenvolvimento positivo do indivíduo, considerando os adolescentes como o futuro da humanidade.
\end{abstract}

Palavras-chave: adolescência, história, teorias sobre adolescência.

\section{Adolescence through the Centuries}

\begin{abstract}
Contemporary western society has extended the period of adolescence, which is no longer seen as a preparation for adult life, but began to make sense of itself as part of the human lifecycle. The present article aims to describe how adolescents have been seen and treated, from antiquity to the present days, as reported by literary or philosophical texts and scientific studies. The bibliographic material on adolescence is characterized by three distinct stages: description of behavior, personal adjustment, and relationship patterns; problem solving through scientific knowledge; and the positive development of the individual, considering adolescents as the future of mankind.
\end{abstract}

Keywords: adolescence, history, theories of adolescence.

A adolescência é definida como um período biopsicossocial que compreende, segundo a Organização Mundial de Saúde - OMS (1965), a segunda década da vida, ou seja, dos 10 aos 20 anos. Esse também é o critério adotado pelo Ministério da Saúde do Brasil (Brasil, 2007a) e pelo Instituto Brasileiro de Geografia e Estatística - IBGE (Brasil, 2007b). Para o Estatuto da Criança e do Adolescente-ECA, o período vai dos 12 aos 18 anos (Brasil, 2007c). Em geral, a adolescência inicia-se com as mudanças corporais da puberdade e termina com a inserção social, profissional e econômica na sociedade adulta (Formigli, Costa \& Porto, 2000).

As mudanças biológicas da puberdade são universais e visíveis, modificando as crianças, dando-lhes altura, forma e sexualidade de adultos. À primeira vista, a adolescência apresenta-se vinculada à idade, portanto, referindo-se à biologia - ao estado e à capacidade do corpo (Santos, 2005). Essas mudanças, entretanto, não transformam, por si só, a pessoa em um adulto. São necessárias outras, mais variadas e menos visíveis, para alcançar a verdadeira maturidade (Berger \&

1 Endereço para correspondência: Universidade Federal de São Paulo, Centro de Atendimento e Apoio ao Adolescente-CAAA. Rua Botucatu 715, Vila Clementino.E-mail: teresaschoen.dped@epm.br; rpetrass@ uol.com.br.

2 A OMS ainda aceita um outro estágio - juventude - que vai dos 15 aos 25 anos, englobando o período intermediário e final da adolescência e o período inicial da vida adulta.

3 Em alguns casos, alguns artigos dessa lei podem ser estendidos aos 21 anos.
Thompson, 1997) - mudanças e adaptações que dirigem o indivíduo para a vida adulta (Bianculli, 1997). Essas incluem as alterações cognitivas, sociais e de perspectiva sobre a vida (Martins, Trindade, \& Almeida, 2003; Santos, 2005). A adolescência é uma época de grandes transformações, as quais repercutem não só no indivíduo, mas em sua família e comunidade.

Kalina e Laufer (1974) entendem a adolescência como o segundo grande salto para a vida: o salto em direção a si mesmo, como ser individual. Eses autores distinguem puberdade de adolescência. Puberdade refere-se aos fenômenos fisiológicos, que compreendem as mudanças corporais e hormonais, enquanto adolescência diz respeito aos componentes psicossociais desse mesmo processo. Melvin e Wolkmar (1993) também fazem essa diferenciação: consideram que, na puberdade, está mais acentuada a maturação física e que a idade real de início pode variar muito, sendo para as meninas em torno dos 10 anos e para os meninos, 12 anos. O ritmo em que ocorrem as mudanças da puberdade também é diferente para as meninas e para os meninos, havendo uma variabilidade dentro do mesmo grupo sexual (Bee, 2003; Serra, 1997). A adolescência, cujo início coincide com a puberdade, é influenciada pelas manifestações desta.

A Organização Mundial de Saúde também considera esses dois conceitos como distintos (Bianculli, 1997). Na puberdade, ocorrem mudanças orgânicas que tendem à maturação biológica adulta com dimorfismo sexual e capacidade reprodutiva; e, na adolescência, há adaptação às novas 
estruturas físicas, psicológicas e ambientais. Por isso, Lidz (1983) e Serra (1997) dizem existir várias adolescências, de acordo com as características de cada pessoa e de seu contexto social e histórico.

Ao mesmo tempo em que é proposta a universalidade do estágio da adolescência, observa-se que ela depende de uma inserção histórica e cultural, que determina, portanto, variadas formas de viver a adolescência, de acordo com o gênero, o grupo social e a geração (Martins \& cols., 2003). A escola, apesar de ser obrigatória para todos os adolescentes, proporciona recursos pessoais e sociais (hábitos de saúde, interações sociais, descoberta de oportunidades, por exemplo) que são aproveitados de maneira distinta pelos alunos (Hargreaves, Earl \& Ryan, 2001; Marturano, Elias \& Campos, 2004; Serra, 1997), o que também influencia na maneira individual de viver a adolescência.

Os adolescentes apresentam diversidade de grupos, atitudes, comportamentos, gostos, valores e filosofia de vida. Como diz Serra (1997), "há diversos mundos e diversas formas de ser adolescente" (p. 29). As experiências vividas ao longo de sua vida marcam o indivíduo como ser único, apesar de compartilhar algumas características com outros jovens.

A sociedade contemporânea ocidental não apenas estendeu o período da adolescência, como também os elementos constitutivos da experiência juvenil e seus conteúdos (Abramo \& Branco, 2005). Adolescência, hoje, não é mais encarada apenas como uma preparação para a vida adulta, mas passou a adquirir sentido em si mesma.

A palavra adolescência vem do latim adolescere, que significa crescer. Segundo Melvin e Wolkmar (1993), a palavra adolescence foi utilizada pela primeira vez na língua inglesa em 1430, referindo-se às idades de 14 a 21 anos para os homens e 12 a 21 anos para as mulheres.

Apesar de ser um estágio desenvolvimental oficialmente inaugurado com Stanley Hall em 1904 (Cole \& Cole, 2004; Melvin \& Wolkmar, 1993; Mussen, Conger, Kagan \& Huston 1995; Santrock, 2003), registros na literatura, especialmente textos sobre educação, documentam algumas características associadas ao adolescente na história da humanidade. Sprinthall e Collins (1999) afirmam que os componentes psicológicos e fisiológicos fundamentais desse período sempre existiram nas pessoas, independente do período histórico ou cultural, embora nem sempre se reconhecessem as características específicas da adolescência. Exemplificando com a amizade, questão muito relevante nessa fase, Brun (2007) escreve que a mesma responde a uma necessidade essencial de encontro com o outro, e esteve presente desde a aurora das civilizações, embora com características das diferentes culturas ou épocas.

Somente nos séculos XIX e XX, acontecimentos sociais, demográficos e culturais parecem ter propiciado o estabelecimento da adolescência como período distinto do desenvolvimento humano (Kimmel \& Weiner, 1998). Dessa forma, entende-se que a psicologia do adolescente tem um longo passado com uma curta história (Pfromm Netto, 1979; Steinberg \& Lerner, 2004).

Informações sobre a adolescência foram recolhidas por meio de estudos sobre as cerimônias de iniciação ocorridas em povos primitivos, prosseguindo com as especulações filosóficas ou textos literários ao longo da história da huma- nidade - que geralmente registravam as classes mais altas - e desembocando nos estudos científicos ocorridos a partir do século XX (Pfromm Netto, 1979).

Embora ainda pouco estudada, a adolescência tem sido vista desde a Antiguidade pelo prisma da impulsividade e excitabilidade. Na Grécia Antiga, os jovens eram submetidos a um verdadeiro adestramento, cujo fim seria inculcar-lhes as virtudes cívicas e militares. Aos 16 anos, podiam falar nas assembleias. A maioridade civil era atingida aos 18 anos, ocasião em que eram inscritos nos registros públicos da cidade (Grossman, 1998). A ginástica era bastante utilizada para o desenvolvimento físico e moral das crianças e jovens. As moças faziam exercícios esportivos a fim de adquirir saúde e vigor para seu futuro de mães de família. Casavam-se aos 15 ou 16 anos. Via-se a fase da puberdade como um período de preparação para os afazeres da vida adulta: no caso do sexo masculino, a guerra ou a política; no caso do sexo feminino, a maternidade. Era possível que alguns jovens se dedicassem à filosofia, geralmente aqueles de famílias mais abastadas que não necessitavam da sua força de trabalho.

Assis e cols. (2003), analisando Platão (séc. IV a.C.), observaram que ele enfatizou características negativas dos jovens, advertindo-os quanto ao uso de bebida alcoólica antes dos 18 anos, achando que era o mesmo que "colocar fogo no fogo". Mas, segundo a análise de Santrock (2003), Platão também considerou que o raciocínio seria uma característica do homem que só apareceria na adolescência. Por isso, as crianças deveriam passar mais tempo brincando e os jovens estudando.

Sprinthall e Collins (2009), Assis e cols. (2003) e Cole e Cole (2004) ressaltam que Aristóteles (séc. IV a.C.) descreveu os jovens, no século IV a.C., como apaixonados, irascíveis e capazes de serem levados por seus impulsos. Ele considerava que os jovens eram exageradamente positivos em suas afirmações e que se imaginavam oniscientes, embora considerasse que o aspecto mais importante da adolescência fosse a habilidade para escolher e que a autodeterminação seria um indício de maturidade. Para ele, o exercício intenso visando competições só deveria ocorrer três anos após o término da puberdade para não comprometer o desenvolvimento biológico.

No início do Império Romano, a educação dos mais jovens ficava a cargo dos pais, sendo uma educação bastante prática, procurando formar o agricultor, o cidadão ou o guerreiro. A partir do século II a.C., as classes mais abastadas passaram a hospedar em suas casas algum mestre grego para educar seus filhos e aqueles que não tinham a mesma possibilidade enviavam seus filhos para escolas. Grossman (1998) conta que os meninos romanos da elite, aos 12 anos, deixavam o ensino elementar e passavam a estudar os autores clássicos e a mitologia, com o objetivo de adornar o espírito. Aos 14 anos, abandonavam as vestes infantis, tendo o direito de fazer tudo o que um jovem gostasse de fazer. Alguns jovens, como complementação de seus estudos, viajavam à Grécia. Aos 16 ou 17 anos, podiam optar pela carreira pública ou entrar para o exército. Não existia "maioridade" legal: o indivíduo era considerado impúbere até que o pai ou o tutor considerasse que estava na idade de tomar as vestes de homem e cortar o primeiro bigode. No período entre a puberdade e o casamento, a indulgência dos pais era admissível, devia-se 
conceder algum privilégio ao calor da juventude. Por outro lado as meninas, aos 12 anos, eram consideradas em idade de casar. O casamento se consumava, no máximo, aos 14 anos, quando então eram consideradas adultas.

Parece que aos poucos, a educação romana perdeu a ideia de praticidade e passou a ser um ornamento intelectual, com isso começa-se a observar uma distância maior entre os jovens de acordo com a classe social, embora muitos escravos recebessem ensinamentos necessários à prática de seus serviços, que podiam até abranger a leitura, cálculos e a filosofia. Entretanto, observamos que desde o início do Império Romano permanecia a ideia de que para tornar um adulto integrado à sociedade era preciso instruir os mais jovens.

Ao longo do século II, difundiu-se uma nova moral que confinava a prática sexual ao casamento. Época em que os médicos prescreviam a ginástica e os estudos filosóficos para tirar dos jovens a "energia venérea", que podia englobar tanto o sexo, quanto o consumo do álcool. Nesse período, acrescentaram-se mudanças na concepção de maioridade. A passagem à idade de homem adulto já não era um fato físico reconhecido por um direito habitual, e sim uma ficção jurídica: de impúbere passava-se a menor legal (Grossman, 1998). Nessa época, surgiu a ideia de que as escolas deveriam ter períodos de descanso entre os momentos de estudo.

Sprinthall e Collins (1999), estudando Santo Agostinho (séc. V), observaram que ele abordou questões que considerava relevantes em relação aos jovens, inclusive certa aversão à escola, sugerindo uma educação mais jovial, alegre, tranquila e com brincadeiras.

$\mathrm{Na}$ Idade Média, o indivíduo vivia em comunidades feudais, as quais se constituíam como um ambiente bastante familiar, onde todos se conheciam. Os papéis, tanto de gênero quanto profissional, eram determinados pela comunidade. Grossman (1998) descreve que, nessa época, o desenvolvimento era entendido como um fenômeno quantitativo e não qualitativo. As crianças e adolescentes eram considerados adultos em miniatura (Garrod, Smulyan, Powers \& Kilkenny, 1995), necessitando apenas de crescer em termos quantitativos em todos os aspectos físicos e mentais da espécie humana. Dessa forma, assim que a criança superava o período de alto risco de mortalidade, ela logo era misturada com os adultos e ia aprendendo as tarefas, crenças e valores que seriam solicitados quando se tornassem adultos (Garrod \& cols., 1995; Grossman, 1998).

Uma forma de o jovem adquirir uma profissão nessa época era através das Corporações de Ofício. Estas eram compostas de três classes: os mestres, donos das oficinas, responsáveis pelo ensino e educação dos aprendizes; os aprendizes, que não recebiam salário, geralmente eram parentes e moravam com o mestre; e o jornaleiro, que já havia terminado o período de aprendizagem e recebia salário.

Entre os nobres, para os mais jovens havia o treinamento para se tornar cavaleiro. Um treinamento bastante intenso e que demorava vários anos. Nas universidades surgiram os cornificianos, que eram estudantes que desejavam uma redução no programa de estudos. $\mathrm{O}$ casamento costumava ser realizado entre 12 ou 15 anos, com a noiva mais nova que o noivo. A partir do séc. XII, a Igreja Católica passou a exigir o consentimento mútuo dos noivos para a união, embora, na prática, os pais pudessem persuadir a filha a dar seu consentimento. Dessa forma podemos observar que os jovens começam a ter algum poder de decisão em relação à sua própria vida (Costa, 2008).

Alguns mosteiros criaram escolas onde se educavam crianças até os 15 anos, independente da classe social. Relatos da época mostram que esses jovens se organizavam em grupos de idades semelhantes para brincar e jogar (Costa, 2002).

A ideia de fases, ou idades da vida, começou a ser mais difundida na Idade Média, observando as diferentes formas de assistência necessárias ao cuidado, sustento e abrigo dos indivíduos e suas funções sociais no decorrer do ciclo vital (Souza \& Homet, 1999). Sob a influência de Aristóteles, as fases correspondiam a períodos de sete anos. A segunda idade era chamada de pueritia e ia dos sete aos 14 anos. A terceira idade (dos 14 aos 21 anos) era chamada de adolescência, porque a pessoa estaria pronta para procriar. Nessa idade o indivíduo cresceria toda a grandeza que lhe fosse devida pela natureza. Para alguns, a adolescência terminava no vigésimo primeiro ano, mas, para outros, durava até os 28 anos, podendo ser estendida até os 30-35 anos (Grossman, 1998).

Erikson (1998) ressalta que Shakespeare (séc. XVI) escreveu um poema intitulado "As sete idades do Homem", onde incluía a idade do estudante, que é resmungão e não gosta da escola e a mocidade - referindo-se ao período da adolescência -, que seria a idade do amante ou a do soldado. Diversos estudiosos da literatura inglesa perguntam se o clássico "Romeu e Julieta" retrataria a rebelião dos jovens contra as tradições dos pais (Brooks-Gunn, 1995).

Grossman (1998) destaca que Rosseau (séc. XVIII), em seu tratado sobre a natureza humana e a educação, sugeriu características da adolescência, as quais continuam influenciando o pensamento atual a respeito desse período. Para Garrod e cols. (1995), esse filósofo enfatizou o processo de desenvolvimento de forma qualitativa. Rousseau considerava a adolescência o período de maior instabilidade e conflito emocional, os quais eram provocados pela maturação biológica. Para ele, tanto as mudanças biológicas quanto as sociais eram acompanhadas por uma mudança nos processos psicológicos, incluindo o desenvolvimento da capacidade de pensar com lógica. Gallantin (1978) observou que para Rousseau o raciocínio era desenvolvido na adolescência, motivo pelo qual, aconselhava que a educação prosseguisse depois dos 12 anos. Santrock (2003) ressalta que esse filósofo considerava a adolescência como um renascimento, período em que o indivíduo recapitula os estágios anteriores da vida, procurando seu lugar na sociedade. Dessa forma, sua opinião era de que tanto a criança quanto o adolescente não eram iguais ao adulto.

De acordo com Ariès (1981), na Idade Moderna, criouse um novo papel para o Estado, o qual passou a interferir, com maior frequência, no espaço social: formas de agir na família, comunidade, grupos religiosos e educacionais. $\mathrm{O}$ desenvolvimento da alfabetização e a facilidade de leitura de livros distanciaram os indivíduos de sua própria comunidade. $\mathrm{O}$ estabelecimento de novas formas de religião ao longo dos séculos XVI e XVII exigiu dos fiéis uma devoção mais íntima e pessoal. Esse movimento inspirou a necessidade de proteger as crianças e jovens das tentações da vida, cuidando da moralidade. O colégio tornou-se, então, uma instituição essencial da sociedade, local de instrução e educação. As 
crianças e adolescentes passaram a ser educados em lugares separados e fechados, sob a autoridade de especialistas adultos. As práticas escolares se destinavam à faixa etária dos 10 aos 25 anos, não havendo a preocupação da separação da população escolar em classes determinadas por faixas etárias. A segunda infância, dessa forma, não se distinguia da adolescência. A longa duração da infância provinha, provavelmente, da indiferença que existia ao fenômeno propriamente biológico - a puberdade.

Não se possuía o conceito do que hoje chamamos adolescência, embora os indivíduos começassem a se organizar em grupos de jovens, que funcionariam como sociedades temporárias, formadas no âmbito das vilas e dos bairros. Essas novas formas de socialização eram destinadas exclusivamente ao público masculino.

No século XIX, a sociedade se tornou uma vasta população anônima, onde as pessoas já não se conheciam. Esse é um período marcado pelo fortalecimento dos Estados Nacionais, pela redefinição dos papéis sociais de mulheres e crianças, pelo avanço acelerado da industrialização e da técnica e pela organização dos trabalhadores (Áries, 1978).

Um duplo movimento percorre as relações entre pais e filhos. De um lado, um investimento crescente no filho, identificado como o futuro da família e, por outro, a visão do filho como objeto de amor. No Brasil, observa-se a criação de escolas para meninas, onde as jovens poderiam, por meio de uma educação intelectual, religiosa e moral, prepararem-se para serem mães dignas e capazes de ensinar seus próprios filhos (Sarat \& Sarat, 2007).

A infância passa a ser encarada como um momento privilegiado da vida, e a criança é identificada como uma pessoa. Nesse momento, a figura do adolescente é delineada com precisão. Alguns marcos indicam o início e o fim dessa etapa: esse período é delimitado, no menino, como o que se estende entre a primeira comunhão e o bacharelado, e na menina, da primeira comunhão ao casamento (Áries, 1978).

Ao longo do século XIX, a adolescência passa a ser reconhecida como um "momento crítico" da existência humana. É temida como uma fase de riscos em potencial para o próprio indivíduo e para a sociedade como um todo.

Em linhas gerais, parece que a ideia do que hoje chamamos adolescência, pressentida a partir do século XVIII (Grossman, 1998), está associada às novas maneiras de viver no grupo social onde o indivíduo está inserido. Com a industrialização e a instituição de sistemas educacionais obrigatórios, ela pode, finalmente, ser mais observada. Podese, então, dizer que a adolescência foi conhecida primeiro pelos educadores.

$\mathrm{Na}$ segunda metade do século XIX, foram organizados os primeiros serviços de saúde dedicados especialmente aos alunos de colégios, fundando-se, em 1884, a Associação de Médicos Escolares (Silber, 1997). Há o interesse médico voltado para os alunos dos internatos, provavelmente mobilizado pelas modificações decorrentes do processo biológico de amadurecimento dos internos (a puberdade) e pelas manifestações decorrentes de seu comportamento e das transformações sexuais. As teorias de Freud começaram a ter mais vulto e a sexualidade, que até então focava apenas a reprodução, começou a ser vista como parte integrante do desenvolvimento do ser humano.
Talvez por necessidades de adaptação à escola, os psicólogos também começaram a estudar a adolescência. Entre eles estava Stanley Hall, que descreveu esse período como uma época de emotividade e estresse aumentados. Legitimou a adolescência como uma etapa que requer estudo e atenção, inaugurando, assim, o estudo científico da adolescência. Para Hall (1925) a adolescência era basicamente biológica. Para ele, a adolescência era entendida como zona de turbulência e contestação, constituindo-se em uma linha de fraturas e erupções vulcânicas no seio das famílias.

A constante vigilância aos adolescentes e o distanciamento com que eram tratados por suas famílias despertaram a necessidade de conquista de sua privacidade. Houve o crescimento de diários íntimos e das amizades com seus pares. A escolha de uma amiga íntima constituía-se em episódio importante na vida de uma adolescente. Era, também, intensa a amizade entre os adolescentes do sexo masculino. Foi criado, em 1908, o Movimento Escoteiro (Baden-Powel, sd). No final do século XIX, já havia sido criada a Associação Cristã de Moços - ACM. Também surgiram diversos movimentos de juventude, ligados ou não a associações profissionais e confrarias, especialmente na Alemanha, após a primeira Grande Guerra, marcados, segundo Haroche (2006), pela rejeição das estruturas adultas vigentes, motivados pelo clima de desencantamento com o status quo.

O século XX foi um período em que as guerras marcaram o desenvolvimento da adolescência. Nos períodos que precederam a I e a II Guerra Mundial, a literatura enfatizava a indolência, indisciplina e preguiça dos adolescentes; enquanto que durante as guerras e nos anos seguintes, os pesquisadores demonstravam a importância do trabalho dos adolescentes para manter a sociedade tal qual eles conheciam (Steinberg $\&$ Lerner, 2004). Amazonas e Braga (2007) relatam que as modificações ocorridas no interior das famílias trouxeram novas posições para seus membros, inclusive o adolescente, pois não era mais o gênero que definia os papéis. Entretanto, Fávero e Abrão (2006) observam que a mídia parece manter os papéis masculinos e femininos, privilegiando o status masculino, em programas dirigidos a adolescentes.

Durante a segunda e a terceira décadas do século $\mathrm{XX}$ foram iniciados diversos estudos do ciclo vital, especialmente nos Estados Unidos e Grã-Bretanha, a partir de programas que acompanhavam as crianças até a vida adulta (Papalia, Olds \& Feldman, 2006). Dessa forma, nas décadas de 40 e 50, começaram a aparecer os resultados de estudos longitudinais, envolvendo grupos diversos de pessoas. Entre eles, podemos citar os estudos da equipe de Havighurst (1957). Suas ideias mostram as tarefas evolutivas como "lições" que o ser humano deve aprender dentro de um período relativamente restrito, para que se desenvolva de modo satisfatório e possa ingressar vitorioso na próxima etapa do ciclo evolutivo. "Em cada fase do desenvolvimento humano, portanto, o indivíduo tem que adquirir algum tipo de habilidade e fazer alguma sorte de ajustamento às demandas da vida" (Rosa, 1988, p. 131).

Havighurst (1957) propôs algumas tarefas evolutivas para o período da adolescência: aceitar o próprio corpo; estabelecer relações sociais mais maduras com os pares de ambos os sexos; desenvolver o papel social de gênero; alcançar a independência dos pais e de outros adultos, com relação aos aspectos emocional, pessoal e econômico; escolher uma 
ocupação e preparar-se para a mesma; preparar-se para o matrimônio e a vida em família; desenvolver a cidadania e comportamentos sociais responsáveis; além de conquistar uma identidade pessoal, uma escala de valores e uma filosofia de vida que guiem o comportamento do indivíduo.

As tarefas acima citadas aparecem de distintas formas em diversos autores que estudam adolescência (Adams, 1998; Alencar, Silva, Silva \& Diniz, 2008; Fávero \& Abraão, 2006; Hargreaves \& cols., 2001; Lidz, 1983; Vargas \& Nelson, 2001). É comum a discussão sobre se são tarefas relacionadas à faixa etária, independentes da cultura, ou se estão restritas à sociedade ocidental, em especial a norte-americana e se ainda valem para hoje em dia.

A questão sobre a universalidade ou não da adolescência é um tema importante e alguns historiadores interessados nesse problema defendem que a adolescência é uma construção social. Os estudos da Antropologia Social revolucionaram essa forma de pensar a adolescência, mostrando uma possibilidade de entender as fases do desenvolvimento humano de forma totalmente nova, ressaltando duas importantes questões: a adolescência não precisa ser, necessariamente, um período turbulento; e as características do desenvolvimento psicossocial não são universais. Em Samoa, sociedade estudada por Margaret Mead (Grossman, 1998; Santrock, 2003; Sprinthall \& Collins, 1999), por exemplo, o desenvolvimento era gradual, calmo e sem impactos profundos. A organização social, a inserção no mundo adulto e as atividades realizadas pelos indivíduos favoreciam uma adolescência relativamente livre de estresse.

Os desenvolvimentistas modernos, especialmente aqueles que estudam a adolescência, tentam explicar como os fatores biológicos, sociais, cognitivos, comportamentais e culturais estão interligados no desenvolvimento, inclusive na transição da infância para a vida adulta. Erikson observou a integração entre esses fatores a partir de seus estudos sobre os problemas desenvolvidos pelos jovens militares que apresentavam dificuldades de se adaptar à vida que levavam antes da II Guerra Mundial, quando seus planos foram interrompidos para servir à pátria (Adams, 1998).

Nos Estados Unidos, durante a década de 50 do século passado, apareceu o fenômeno denominado "juventude transviada" ou "rebelde sem causa" (Grossman, 1998). Já começava a se delinear, de modo bastante claro, uma consciência etária - a oposição jovem / não-jovem. Marty (2006) afirma que a adolescência está amalgamada na violência, entretanto esta não é exclusiva dos jovens, embora, para essa autora, um determinado nível de violência seja próprio dessa fase do desenvolvimento. Considera a adolescência como um processo de arrombamento pubertário, tal como os bombardeios aéreos durante as guerras. Aberastury e cols. (1980) identificaram a "Síndrome da Adolescência Normal", onde diversos comportamentos considerados patológicos em outros estágios do ciclo vital são considerados esperados e normais no período da adolescência.

Os anos 60 inauguram um novo estilo de mobilização e contestação social, os quais contribuíram para a percepção da adolescência como uma subcultura (Garrod \& cols., 1995). Os jovens passaram a negar todas as manifestações visíveis dessa sociedade. Esse movimento transformaria a juventude em um grupo, com um novo foco de contestação. Surgiu um termo novo: contracultura. Inicialmente, o fenômeno seria caracterizado por seus sinais mais evidentes: cabelos compridos, roupas coloridas, misticismo, um tipo de música e drogas, significando uma nova maneira de pensar, modos diferentes de se relacionar com o mundo e com as pessoas. De um lado, surgia o "movimento hippie" com sua filosofia; por outro lado, a introdução da política nos movimentos estudantis universitários (Grossman, 1998). Brun (2007) relata que muitos pais se ressentem de certas amizades de seus filhos, quando, influenciados pelo grupo de pares, cometem transgressões sociais ou sexuais. Entretanto, não eram todos os jovens que estavam em um ou outro movimento. Para Mussen, Conger e Kagan (1977) trata-se de uma tendência de assumir que os adolescentes sejam todos iguais - uma supersimplificação que não recebe apoio de estudos sérios. Estudos atuais enfocam essa fase do desenvolvimento, observando diversas variáveis que podem influenciar o indivíduo, como raça, sexo, nível socioeconômico, história pessoal, contexto, cultura, entre tantas.

Erikson (1972), utilizando as propostas da psicanálise e os achados da Antropologia Cultural, propôs a Teoria Psicossocial, na qual sugere que o ambiente também participa na construção da personalidade do indivíduo. Sifuentes, Dessen e Oliveira (2007) entendem que as etapas do ciclo vital, e, portanto, a adolescência, são observações de fatos sociais e psicológicos, cujas características dependem do contexto em que estão inseridas. Essa mudança, na visão do desenvolvimento, é de grande importância, abrindo novas fronteiras para o entendimento do desenvolvimento e, mais especificamente, da adolescência.

$\mathrm{Na}$ virada para o séc. XXI, apareceu a expressão "onda jovem" para denominar o grande número de indivíduos que estão nessa faixa etária, devido a explosão da taxa de natalidade que ocorreu no início da década de 80 do século anterior. Esses jovens se depararam com um cenário econômico adverso, dificuldades para arrumar e se manter no emprego, incremento dos problemas sociais, especialmente os urbanos (Brasil, 1999; Matheus, 2003), modificações nos valores sociais, falta de perspectivas, diminuição da influência e controle tradicionalmente exercida pela família, igreja e comunidade (Vargas \& Nelson, 2001). Ao mesmo tempo, a criança e o adolescente passam a ser considerados sujeitos de direito e em fase especial de desenvolvimento, afirmando a ideia de proteção integral do estado (Espindula \& Santos, 2004). À medida que os governos tomam consciência da importância de se proteger o desenvolvimento do ser humano, a adolescência torna-se um período mais identificável no ciclo vital (Sprinthall \& Collins, 1999).

Com esse histórico da posição dos adolescentes e da adolescência na sociedade, através dos séculos, pode-se considerar esse estágio uma invenção cultural (Rappaport, 1982) ou um luxo (Serra, 1997), que só sociedades ou grupos sociais mais desenvolvidos se permitem. A concepção da adolescência parece estar relacionada à democratização da educação e ao surgimento de leis trabalhistas (Gallantin, 1978). Segundo Bucher-Maluschke (2007), a lei é percebida como protegendo apenas os mais ricos e não alcança as camadas menos favorecidas economicamente, onde os relacionamentos são permeados pela força bruta ou pela "lei do mais forte". Percebe-se uma intromissão maior do serviço 
público junto aos adolecentes, especialmente a polícia e o Poder Judiciário. Amazonas e Braga (2007) colocam que esse fenômeno começou a ocorrer no Brasil a partir de 1900, dependendo da região geográfica e das camadas sociais. Ainda encontramos grupos sociais que compreendem a criança/ adolescente como um ser menos importante, que ainda não adquiriu o status de pessoa (Morais, Cerqueira-Santos, Moura, Vaz \& Koller, 2007).

As culturas mais sofisticadas tecnicamente retardam o ingresso do jovem nas estruturas sociais, sendo cada vez maior a exigência de estudos e especialização para ingressar no mercado de trabalho. Consequentemente, o indivíduo precisa de mais tempo para cumprir as tarefas da adolescência, e esse período se estende. Embora, atualmente, a idade média de casamento da mulher brasileira seja 24,1 anos, quase um terço das jovens já teve pelo menos um filho (Brasil, 1999). Gallantin (1978), Rappaport (1982), Grossman (1998) e Santrock (2003), entre outros, destacam o fato evidenciado por alguns filósofos de que a adolescência começa na biologia e termina na cultura (Mussen \& cols., 1995), tanto assim que nas sociedades mais simples essa fase pode ser breve (Traverso-Yepez \& Pinheiro, 2002). Os psicólogos evolucionistas partem do princípio de que o ser humano é uma espécie animal com maior nível de sofisticação e que seus algoritmos mentais foram desenvolvidos na época em que éramos caçadores/coletores e podem não estar bem adaptados à sociedade contemporânea. É necessária uma reorganização comportamental decorrente da luta interna entre os genes, cérebro, educação recebida, história individual no seu grupo social e estímulos (Lopes \& Vasconcelos, 2008).

A Organização Mundial da Saúde (1965) utiliza o termo juventude para evocar a faixa etária entre 15 e 24 anos, em função do prolongamento da fase na qual não são assumidas as responsabilidades ditas adultas. Postergou-se o matrimônio, ampliou-se a necessidade de permanecer no lar paterno (emancipação tardia), aumentou-se o número de nascimentos fora do matrimônio - fatores que levam o indivíduo a conviver com mais pessoas de diferentes idades e ambientes, sem laços consanguíneos com a maioria delas, com diferentes escalas de valores, ideias e crenças (Vargas \& Nelson, 2001), e por mais tempo. As modificações introduzidas na vida moderna exigem que os indivíduos tenham mais tempo para cumprir as tarefas evolutivas propostas para a referida faixa etária.

A escola também modificou seu papel em relação ao adolescente: até tempos atrás, esperava-se que ele fosse preparado para assumir uma profissão, portanto, os cursos costumavam ter uma vertente profissionalizante bastante acentuada. Atualmente, a educação básica busca somente fornecer subsídios para o desenvolvimento pleno do ser humano, sem a preocupação da profissionalização.

Sifuentes e cols. (2007) concordam que as mudanças e continuidades que o adolescente vivencia no seu processo de desenvolvimento tem relação com essa fase específica (mudanças físicas e cognitivas) e também com às modificações que ocorrem na sociedade em que participa.

Da mesma forma que observamos mudanças no entendimento do que é adolescência, também observamos mudanças em como os teóricos abordam essa etapa. Hoje observamos uma perspectiva de estudar todo o ciclo vital, considerando, então, a adolescência como mais uma etapa, com características próprias que atuarão na construção das trajetórias de vida de cada indivíduo, dentro de um contexto sóciocultural (Sifuentes \& cols., 2007).

Steinberg e Lerner (2004) observaram três perspectivas: a primeira, compreendida entre as décadas de 50 a 80 do século passado, enfatizava os estudos descritivos de padrões de comportamento, ajustamento pessoal e relacionamento, além de estudos sobre as possíveis trajetórias que os indivíduos podem seguir ao longo do desenvolvimento. A segunda perspectiva, da década de 80 aos dias de hoje, enfatiza a aplicação dos conhecimentos científicos na resolução de problemas reais. A terceira perspectiva está interessada em promover o desenvolvimento positivo do indivíduo, especialmente ao se conscientizar que os adolescentes representam o futuro da humanidade. Os cientistas estão engajados em transformar esse coorte em adultos capazes e comprometidos consigo, suas famílias, comunidades e sociedade em geral.

Esperamos ter mostrado como o entendimento da adolescência - as exigências e comportamentos - é composto pelas variáveis presentes nas culturas em distintas épocas, as quais, para responder a novas demandas, materializavam seus ideais em instituições e comportamentos que buscavam facilitar a assunção dos direitos e deveres do adulto.

\section{Referências}

Aberastury, A., Knobel, M., Ferrer, E. S. L., Goldstein, R. Z., Jarast, S. G., Kalina, E., Paz, L. R., \& Rolla, E. H. (1980). Adolescência. Porto Alegre: Artes Médicas.

Abramo, H. W., \& Branco, P. P. M. (2005). Retratos da juventude brasileira: análises de uma pesquisa nacional. São Paulo: Fundação Perseu Abramo e Instituto Cidadania.

Adams, G. R. (1998). The objective measure of ego identity status: A reference manual. sl:se.

Alencar, R. A., Silva, L., Silva, F. A., \& Diniz, R. E. S. (2008). Desenvolvimento de uma proposta de educação sexual para adolescentes. Ciência \& Educação, 14, 159-168.

Amazonas, M. C. L. A., \& Braga, M. G. R. (2006). Reflexões acerca das novas formas de parentalidade e suas possíveis vicissitudes culturais e subjetivas. Ágora, 9, 177-191.

Ariès, P. (1981). História social da criança e da família $\left(2^{\mathrm{a}}\right.$ ed.). Rio de Janeiro: LTC.

Assis, S. G., Avanci, J. Q., Silva, C. M. F., Malaquias, J. V., Santos, N. C., \& Oliveira, R. V. C. (2003). A representação social do ser adolescente: um passo decisivo na promoção da saúde. Ciência \& Saúde Coletiva, 8, 669-679.

Baden-Powell. (sd). Guia do chefe escoteiro ( $4^{\mathrm{a}} \mathrm{ed}$.). Rio de Janeiro: Escoteira.

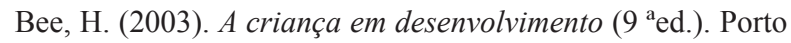
Alegre: Artmed.

Berger, K. S., \& Thompson, R. A. (1997). El desarrollo de la persona desde la niñez a la adolescencia (4 $4^{\mathrm{a}}$ ed.). Madrid: Medica Panamericana.

Bianculli, C. H. (1997). Realidad y propuestas para continencia de la transición adolescente en nuestro medio. Adolescência Latinoamericana, 1, 31-39.

Brasil (1999). População jovem no Brasil. Rio de Janeiro: IBGE. 
Brasil (2007a). Saúde de adolescentes e jovens. Caderneta. Retirado em 21/03/2007, de http://portal.saude.gov.br/saude/.

Brasil (2007b). Indicadores sociais. Crianças e adolescentes. Retirado em 21/03/2007, de http://www.ibge.gov.br/home/.

Brasil (2007c). Lei $n^{\circ}$. 8069, de 13 de julho de 1990. Retirado em 20/03/2007, de http://www.planalto.gov.br/ccivil_03/Leis/ L8069.htm.

Brooks-Gunn, J. (1995). The invention of adolescence. Retirado em 10/05/2010, de http://www.psychologytoday.com/ articles/199501/the-invention-adolescence.

Brun, D. (2007). A gramática amorosa da amizade. Ágora, 10, 311-319.

Bucher-Maluschke, J. S. N. F. (2007). Lei, transgressões, famílias e instituições: elementos para uma reflexão sistêmica. Psicologia: Teoria e Pesquisa, 23, 83-87.

Cole, M., \& Cole, S. (2004). O desenvolvimento da criança e do adolescente. Porto Alegre: Artmed.

Costa, R. (2002). A educação infantil na Idade Média. Videtur, 17, 13-20.

Costa, R. (2008). A educação na Idade Média: a retórica nova (1301) de Ramon Llull. Notadum, 16, 29-38.

Erikson, E. H. (1972). Identidade, juventude e crise. Rio de Janeiro: Zahar

Erikson, E. H. (1998). O ciclo de vida completo. Porto Alegre: Artes Médicas.

Espindula, D. H. P., \& Santos, M. F. S. (2004). Representações sobre a adolescência a partir da ótica dos educadores sociais de adolescentes em conflito com a lei. Psicologia em Estudo, 9, 357-367.

Fávero, M. H., \& Abrão, L. G. M. (2006). Malhando o gênero: o grupo focal e os atos da fala na interação de adolescentes com a telenovela. Psicologia: Teoria e Pesquisa, 22, 175-182.

Formigli, V. L. A., Costa, M. C. O., \& Porto, L. A. (2000). Evaluation of a comprehensive adolescent health care service. Cadernos de Saúde Pública, 16, 831-841.

Gallantin, J. (1978). Adolescência e individualidade: uma abordagem conceitual da psicologia da adolescência. São Paulo: Harper \& Row do Brasil.

Garrod, A., Smulyan, L., Powers, S., \& Kilkenny, R. (1995). Adolescent portraits: Identity, relationships, and challenges ( $2^{\mathrm{a}} \mathrm{ed}$.). Boston: Allyn and Bacon.

Grossman, E. (1998). La adolescencia cruzando los siglos. Adolescencia Latinoamericana, 1, 68-74.

Hall, G. S. (1925). Adolescence: Its psychology and its relations to physiology, anthropology, sociology, sex, crime, religion and educations (Vol I e II). New York: D. Appleton.

Hargreaves, A., Earl, L., \& Ryan, J. (2001). Educação para mudança: recriando a escola para adolescentes. Porto Alegre: Artes Médicas.

Haroche, C. (2006). Subjetividades e aspirações: os movimentos de juventude na Alemanha (1918-1933). Ágora, 9, 9-25.

Havighurst, R. J. (1957). Human development and education. New York: Longmans, Green and Co.Kalina, E., \& Laufer, H. (1974). Aos pais de adolescentes. Rio de Janeiro: Cobra Morato.

Kimmel, D. C., \& Weiner, I.B. (1998). La adolescencia: una transición del desarrollo. Barcelona: Ariel.

Lidz, T. (1983). A pessoa: seu desenvolvimento durante o ciclo vital. Porto Alegre: Artes Médicas.

Lopes, R. G., \& Vasconcellos, S. (2008). Implicações da teoria da evolução para a psicologia: a perspectiva da psicologia evolucionista. Estudos de Psicologia, 25, 123-130.
Martins, P. O., Trindade, Z. A., \& Almeida, A. M. O. (2003). O ter e o ser: representações sociais da adolescência entre adolescentes de inserção urbana e rural. Psicologia: Reflexão e Crítica, 16, 555-568.

Marturano, E. M., Elias, L. C. S., \& Campos, M. A. S. (2004). $\mathrm{O}$ percurso entre a meninice e a adolescência: mecanismos de vulnerabilidade e proteção. Em Marturano, E. M., Linhares, M. B. M. \& Loureiro, S. R. (Orgs). Vulnerabilidade e proteção: indicadores na trajetória de desenvolvimento do escolar (pp.251288). São Paulo: Casa do Psicólogo.

Marty, F. (2006). Adolescência, violência e sociedade. Ágora, 9, 119-131.

Matheus, T. C. (2003). O discurso adolescente numa sociedade na virada do século. Psicologia USP, 14, 85-94.

Melvin, L., \& Wolkmar, F.R. (1993). Aspectos clínicos do desenvolvimento na infância e adolescência ( $3^{\mathrm{a}}$. ed). Porto Alegre: Artes Médicas.

Morais, N. A., Cerqueira-Santos, E., Moura, A. S., Vaz, M., \& Koller, S. (2007). Exploração sexual comercial de crianças e adolescentes: um estudo com caminhoneiros brasileiros. Psicologia: Teoria e Pesquisa, 23, 263-271

Mussen, P. H., Conger, J. J., \& Kagan, J. (1977). Desenvolvimento e personalidade da criança. São Paulo: Harbra.

Mussen, P. H., Conger, J. J., Kagan, J., \& Huston, A. C. (1995). Desenvolvimento e personalidade da criança. São Paulo: Harbra.

Organização Mundial da Saúde (1965). Problemas de la salud de la adolescencia. Informe de un comité de expertos de la O.M.S (Informe técnico $n^{\circ} 308$ ). Genebra.

Papalia, D. E., Olds, S. W., \& Feldman, R. D. (2006). Desenvolvimento humano ( $8^{\mathrm{a}}$ ed.). Porto Alegre: Artmed.

Pfromm Netto, S. (1979). Psicologia da adolescência. São Paulo: Pioneira.

Rappaport, C. R. (1982). Psicologia do desenvolvimento: A idade escolar e a adolescência (Vol. 4). São Paulo: E.P.U.

Rosa, M. (1988). Psicologia evolutiva: problemática do desenvolvimento ( $4^{\mathrm{a}}$ ed.). Petrópolis: Vozes.

Santos, L. M. M. (2005). O papel da família e dos pares na escolha profissional. Psicologia em Estudo, 10, 57-66.

Santrock, J. W. (2003). Adolescência ( $8^{\mathrm{a}}$ ed.). Rio de Janeiro: LTC.

Sarat, M., \& Sarat, L. (2007). Histórias de viajantes e suas missões civilizadora. Em Anais do X Simpósio Internacional Processo Civilizador (pp. 1-8). Campinas: UNICAMP. Retirado em 29/4/2008, de http://www.fef.unicamp.br/sipc/anais8/Magda\%20 Sarat\%20UNIMEP\%20.pdf

Serra, E. (1997). Adolescência: perspectiva evolutiva. Em Anais do VII Congreso INFAD (pp. 24-28). Oviedo (Espanha).

Sifuentes, T. R., Dessen, M. A., \& Oliveira, M. C. S. L. (2007). Desenvolvimento humano: desafios para a compreensão das trajetórias probabilísticas. Psicologia: Teoria. e Pesquisa, 23, 379-385.

Silber, T. J. (1997). Medicina de la adolescencia: Una nueva subespecialidad de la Pediatría y la Medicina Interna en la América del Norte. Adolescencia Latinoamericana, 1, 11-15.

Souza, N. A., \& Homet, R. (1999). Los viejos y la vejez en la Edad Media. Sociedad e imaginario. Revista Brasileira de História, 19, 313-318.

Sprinthall, N. A., \& Collins, W. A. (1999). Psicologia do adolescente: uma abordagem desenvolvimentista ( $2^{\mathrm{a}}$ ed.). Lisboa: Fundação Calouste Gulbenkian. 
Steinberg, L., \& Lerner, R. M. (2004). The scientific study of adolescence: A brief history. The Journal of Early Adolescence, 24, 45-54.

Traverso-Yepez, M. A., \& Pinheiro, V. S. (2002). Adolescência, saúde e contexto social: esclarecendo práticas. Psicologia \& Sociedade, 14, 133-14.

Vargas, C., \& Nelson, A. 2001. Cambios en la familia: repercusiones en la práctica pediátrica. Revista Chilena de Pediatria, $72,77-80$.
Recebido em 10.09.2007

Primeira decisão editorial em 19.03.2010

Versão final em 13.05.2010

Aceito em 13.05.2010 